\title{
Analysis of Amplitude Dependence of Internal Damping of AZ31 and AZ61 Alloys in Initial State and after Deformation
}

Milan Uhríčik, Zuzana Dresslerová, Peter Palček, Mária Chalupová, Patrícia Hanusová

Faculty of Mechanical Engineering, Department of Materials Engineering, University of Žilina. Univerzitná 8215/1, 010 26 Žilina. Slovak Republic. E-mails: milan.uhricik@fstroj.uniza.sk, zuzana.dresslerová@fstroj.uniza.sk, peter.palcek@fstroj.uniza.sk,maria.chalupova@fstroj.uniza.sk, patricia.hanusova@fstroj.uniza.sk

The article is focused on the analysis of amplitude dependence on the internal damping of magnesium alloys in initial state and after deformation. Resonance method, based on continuous excitation of oscillations of the specimen, was used in experimental measurements, with the entire apparatus vibrating at a frequency close to the resonance. The damping capacity, characterized by dissipation of mechanical energy, was examined in magnesium alloys of AZ31 and AZ61 type. These alloys have different contents of the main alloying elements and it is expected that they will have a significant impact on the measured course of amplitude dependencies of internal damping. Dependence of internal damping on amplitude was measured on test specimens after homogenization annealing without plastic deformation of the material and after different degrees of plastic deformation to determine the critical strain amplitude.

Keywords: Magnesium alloy, Internal damping, Deformation, Amplitude dependence

\section{Introduction}

Magnesium alloys are characterized by low density, high specific strength, high specific rigidity, and so on. Mainly for these reasons, the applications of magnesium alloys are widespread in many industrial fields, such as automotive industry, aeronautic industry and microelectronics industry. However, the use of these alloys has been limited to a narrow range due to relatively low strength and ductility $[1,2]$. During last decades magnesium alloys are also considered as suitable biodegradable materials which can be used for traumatology degradable implants or even degradable stents. In comparison with biodegradable polymers, ceramics or bioactive glasses, biodegradable $\mathrm{Mg}$ alloys are favoured for their higher tensile strength and for a Young's modulus that is closer to that of natural bone [3].

By measuring the internal damping processes of microplastics are evaluated and examined and the energy dissipation within the metal is also evaluated. The mecha- nism of microplasticity can be evaluated by various dependencies (frequency, time, temperature and amplitude), which characterize the kinetic of accumulation of fatigue damage in long-time loading. By measuring the energy dissipation in a material, it is possible to determine elastic characteristics, the modulus of elasticity, the degree of stress relaxation in the material and others [4]. The ability of the solid to irreversibly disperse energy under mechanical stress is called the internal damping. The time that is required to reach the equilibrium value of deformation is determined by various processes related to the redistribution of atoms, magnetic moments and temperature of the solid under external stresses [5].

\section{Materials for experiment}

For the study and measurement of internal damping the commercially available magnesium alloys, especially AZ31 and AZ61, were used as experimental materials. The chemical composition of these alloys was examined by spark emission spectrometer SPEKTROMAXx and results are shown in Table 1.

Tab. 1 Chemical composition of magnesium alloys in wt. \%

\begin{tabular}{|c|c|c|c|c|c|c|c|c|}
\hline Elements & Al & Zn & Si & Mn & P & Fe & Cu & Mg \\
\hline AZ31 & 2.980 & 0.655 & 0.067 & 0.202 & 0.002 & 0.007 & $<0.001$ & Balance \\
\hline AZ61 & 6.880 & 1.200 & 0.079 & 0.229 & 0.005 & 0.007 & 0.005 & balance \\
\hline
\end{tabular}

Before measuring of internal damping was performed, the experimental material was subjected to the metallographic analysis. The microstructures were studied using an optical microscope Neophot 32 and scanning electron microscope TESCAN Vega II LMU upon deep etching $[6,7]$. The microstructure of alloys was evaluated in their initial state and after homogenization annealing (annealing at $390^{\circ} \mathrm{C}$ with residence time of 22 hours and rapid cooling in water).

The microstructure of the AZ31 magnesium alloy
(Fig. 1) was significantly dendritic. After casting, dendrites emerge from the melt as first, formed by a solid solution $\delta$ (solid solution of the additive elements of aluminum and zinc in magnesium). Intermetallic phase $\mathrm{Mg}_{17} \mathrm{Al}_{12}$ (phase $\gamma$ ), eutectic (formed by solid solution $\delta$ and phase $\gamma$ ) and other phases formed by combining the additive elements in the magnesium were found in the interdendritic areas. A fine discontinuous precipitate occurred at the borders of phase $\gamma$. 

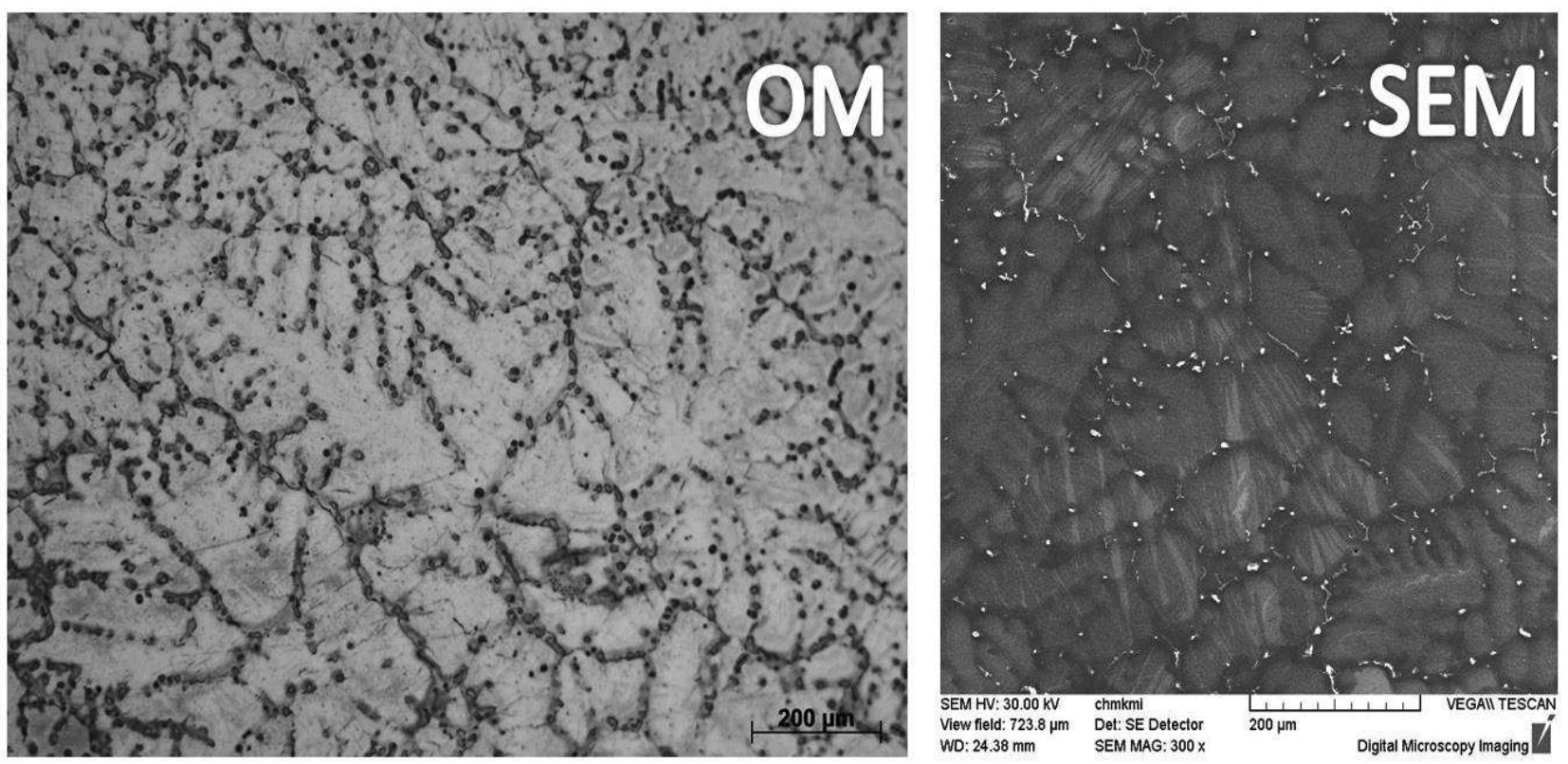

Fig. 1 Microstructure of magnesium alloy AZ31 as cast, etch. Picric acide (optical microscope (OM) - 100x magnification; scanning electron microscope (SEM) - 300x magnification)

The heat treatment caused the formation of a polyedric microstructure in the AZ31 magnesium alloy (Fig. 2 ), the dissolution of a part of the intermetallic phases formed during the crystallization of the melt after casting and the diffusion of alloying elements into the matrix.
Some phases (mainly based on $\mathrm{Mn}-\mathrm{Fe}$ and $\mathrm{Si}$ ) remained undissolved due to their limited solubility at the annealing temperature used (the annealing temperature and diffusion rate are low, so they did not dissolve in 22 hours).
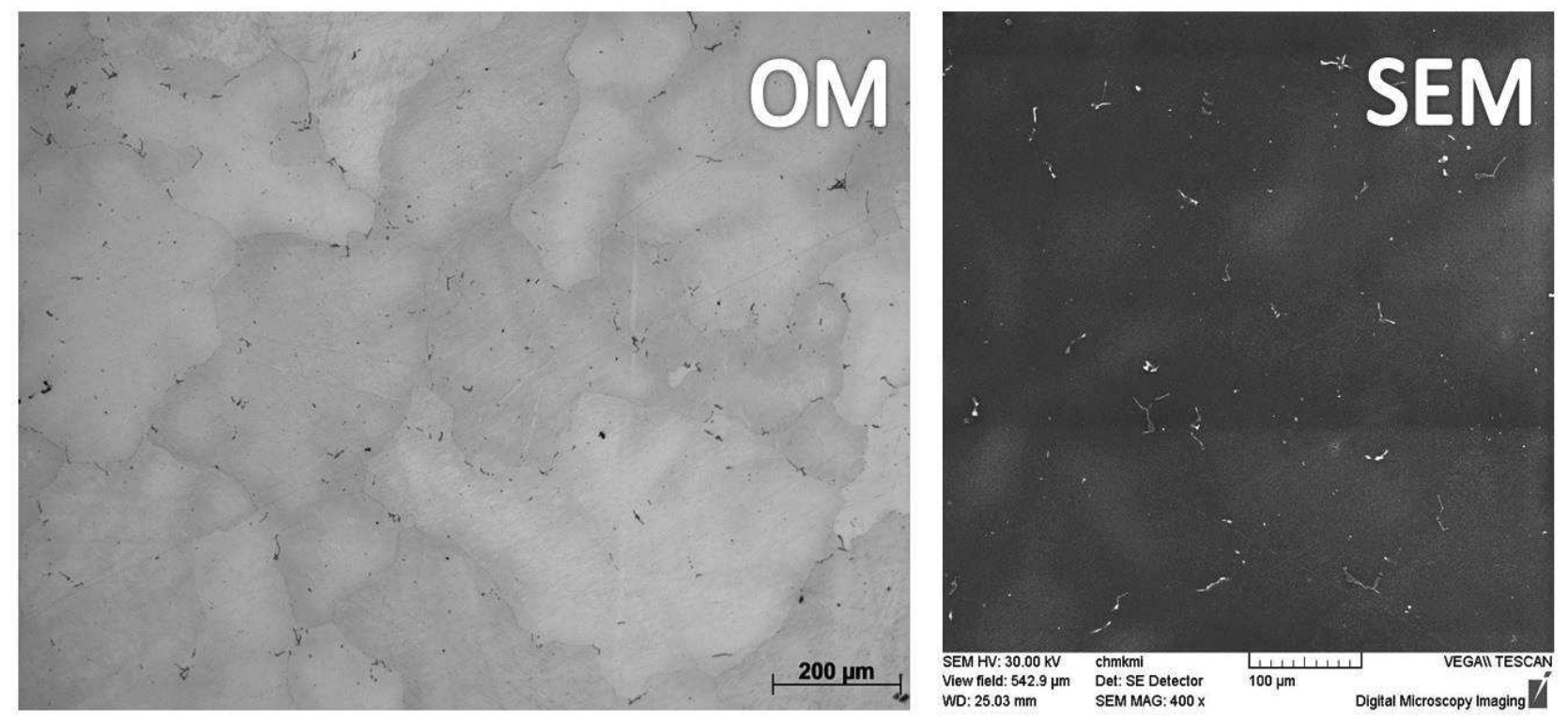

Fig. 2 Microstructure of magnesium alloy AZ31 after the heat treatment, etch. Picric acide (optical microscope (OM) 100x magnification; scanning electron microscope (SEM) - 400x magnification)

The microstructure of the AZ61 magnesium alloy (Fig. 3) was very similar to that of AZ31, i.e. it was created by a solid solution of the additive elements of aluminum and zinc in magnesium, which crystallized in the form of dendrites. Phase $\gamma$, eutectic and the other phases formed in the interdendritic areas by combining additive elements in the magnesium. A discontinuous precipitate was excreted in the interdendritic areas, not present in the AZ31 alloy. A slightly higher content of additive elements caused a slight increase in the amount of eutectic and phase $\gamma$. 

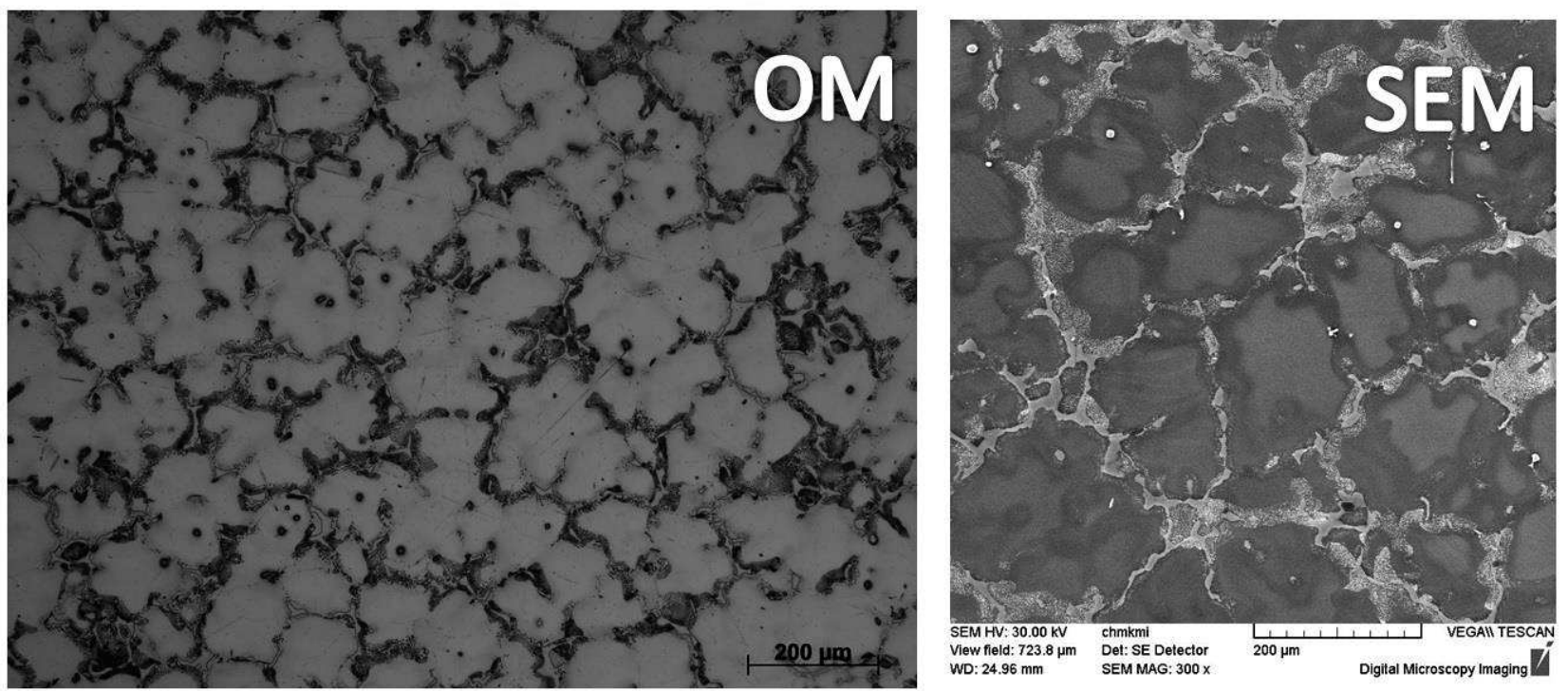

Fig. 3 Microstructure of magnesium alloy AZ61 as cast, etch. Picric acide (optical microscope (OM) - 100x magnification; scanning electron microscope (SEM) - 300x magnification)

The microstructure of the AZ61 magnesium alloy (Fig. 4) was formed by polyedric grains after the heat treatment. Part of the intermetallic phases was dissolved in the alloy and then the alloying elements were diffused into the matrix. A completely insoluble phase $\gamma$ occurred at some places along the grain boundaries and undissolved particles based on $\mathrm{Mn}-\mathrm{Fe}$ and $\mathrm{Si}$ were found in the grains.
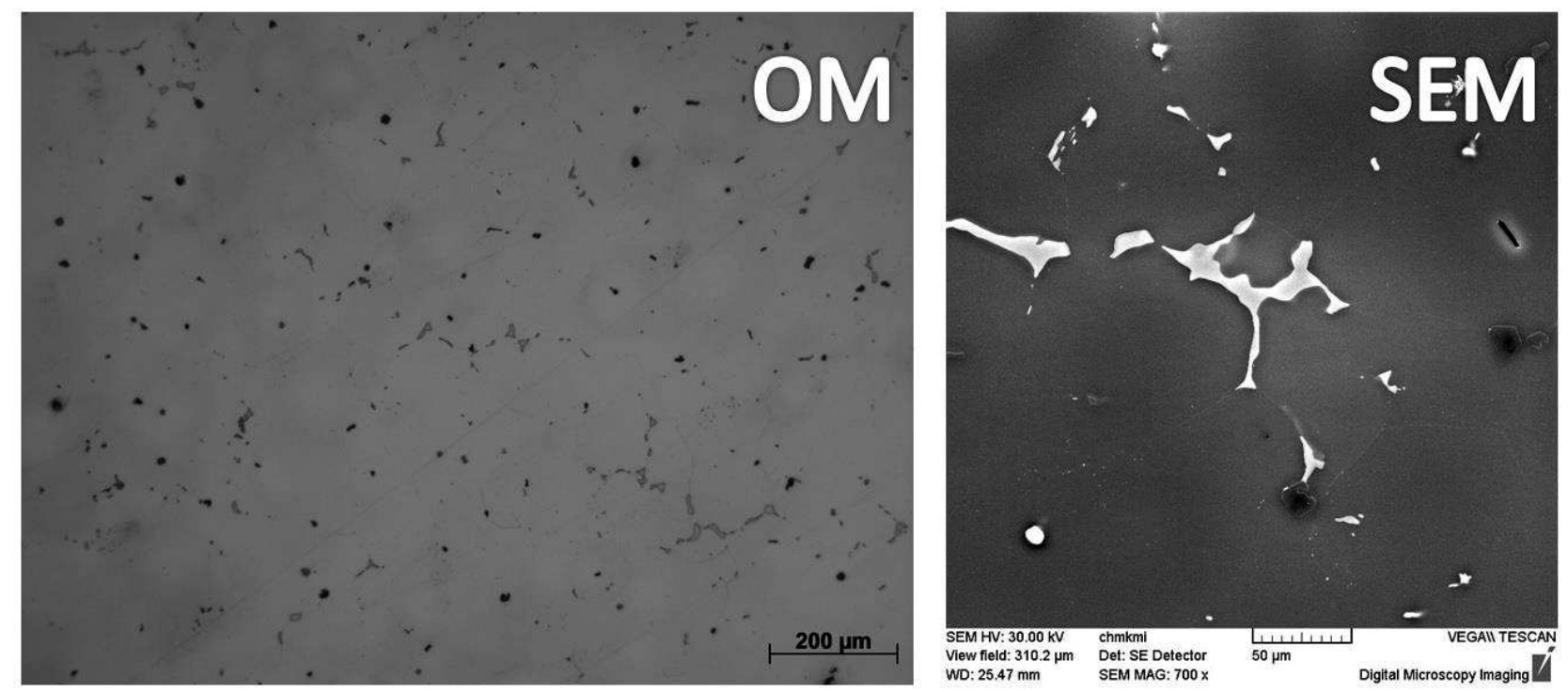

Fig. 4 Microstructure of magnesium alloy AZ61 after the heat treatment, etch. Picric acide (optical microscope (OM) $100 x$ magnification; scanning electron microscope (SEM) - 700x magnification)

\section{Equipment for experiment}

The experimental equipment, used at Department of Materials Engineering, University of Žilina, consists from mechanical and electronical part. The mechanical part (Fig. 5) consists of three basic parts: a transducer, a rod and a specimen. The transducer is the most difficult part, which serves like the source and at the same time like the detector of ultrasonic waves. The rod, which is made of titanium, has a cylindrical shape with a diameter of $12 \mathrm{~mm}$. Its function is to isolate the heat from the test specimen, which is heated in a furnace and the transducer then maintains at a constant room temperature. The last part is the specimen. Dimensions and shape of the test specimen are designed to fulfill the resonance condition that means the natural frequency must be approximately the same as the frequency of the test equipment $\pm 10 \mathrm{~Hz}$. Usually this is used with a tapered shape rod shaft in the middle [8]. 


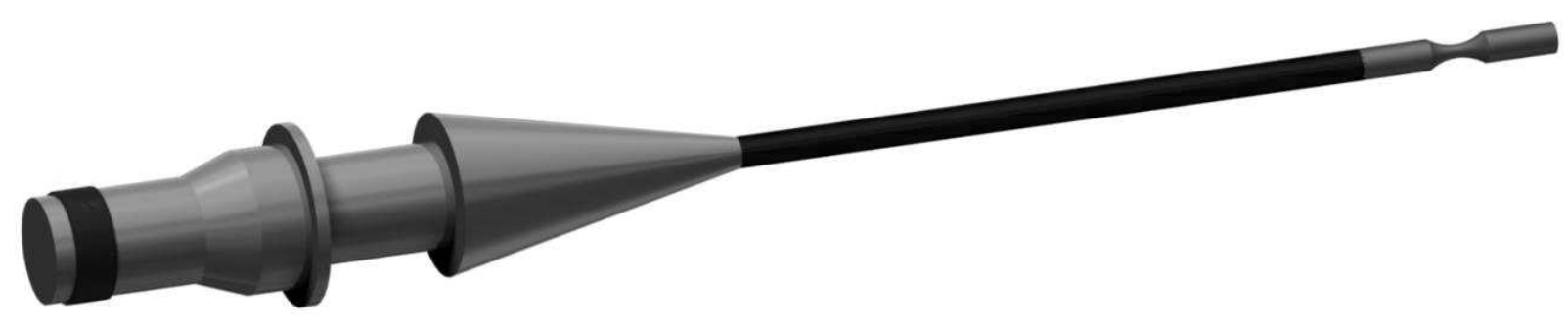

Fig. 5 An ultrasonic resonance device for internal damping measurement

Before measuring of internal damping could take place, it was necessary to determine the dependence of the amplitude of displacement of the test rod from the current input to the ultrasonic transducer using the MTI2100 measuring device. After that it was also necessary to determine the amplitude of deformation from the amplitude of displacement, which was done in the ANSYS program. Results of the FEM analysis (Fig. 6) point to the place where the greatest deformation occurs.

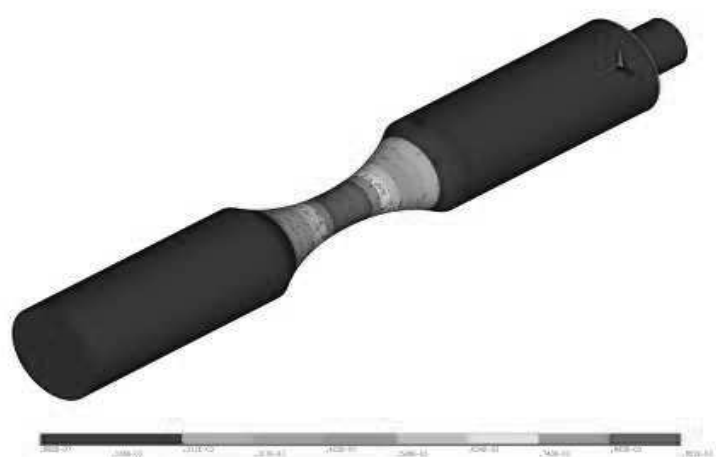

Fig. 6 Result of FEM analysis

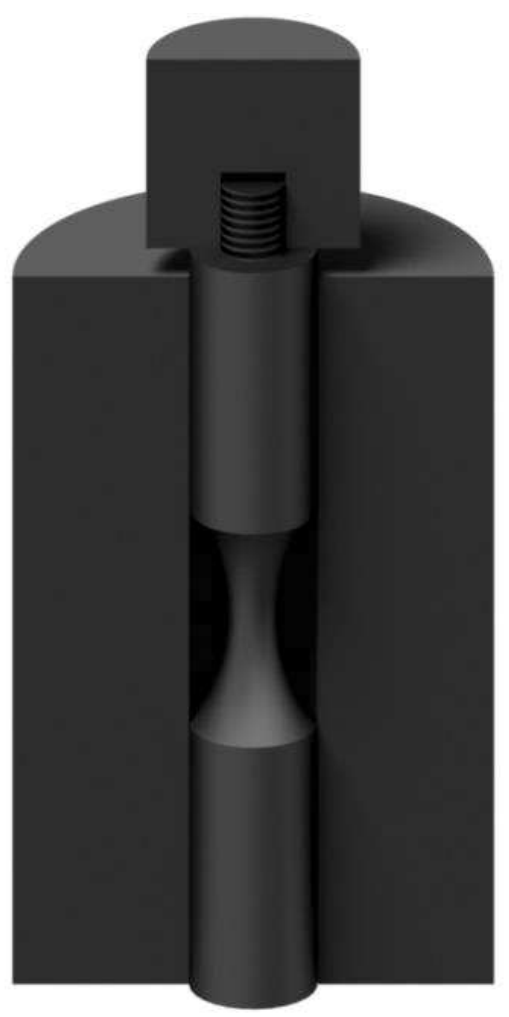

Fig. 7 A device designed to perform the plastic deformation on test bars
For the plastic deformation, this is a uniaxial deformation when test bars are subjected to a compressive deformation. Test bars were placed in a steel device (Fig. 7) to prevent their offset during the deformation and were loaded in one direction with a force, that gradually increased. After the application of each load, the plastic deformation was calculated, and one internal damping course was measured. The shape of the test bar makes the plastic deformation likely to occur in its shaft where the specimen is tapered. For this reason, two marks were placed on the shaft, $4 \mathrm{~mm}$ apart. The plastic deformation was calculated from the varying distance of these two marks after removal of mechanical stress.

\section{Measurement of internal damping}

Experimental measurements were performed at constant temperature $\left(20^{\circ} \mathrm{C}\right)$ and a constant frequency of oscillations (but in fact the frequency slightly shifted to lower values due to the change in the dynamic modulus of elasticity). In amplitude-dependent measurements, the control program allows to enter the value of vibration voltage as the input value, which was $100 \mathrm{mV}$ at the beginning of the experiment. Measurements were performed in steps of $100 \mathrm{mV}, 200 \mathrm{mV}$ or $300 \mathrm{mV}$ in selected load ranges.

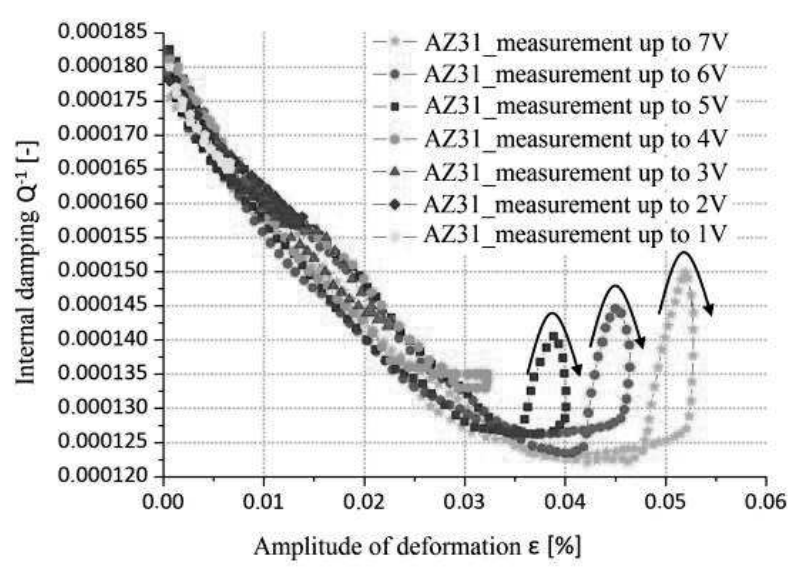

Fig. 8 Amplitude dependence of the internal damping of AZ31 magnesium alloy

Measurement of internal damping was performed on heat treated test rods (annealing at $390^{\circ} \mathrm{C}$ with residence time of 22 hours and rapid cooling in water) to ensure a homogeneous structure. The measurement was carried 
out seven times, with the maximum amplitude of the vibration voltage increasing from $1 \mathrm{~V}$ to $7 \mathrm{~V}$. These measurements were performed in such a way that the amplitude of the vibration voltage was gradually increased in steps of $100 \mathrm{mV}$ to a selected maximum value. After reaching this value, there was a controlled decline back to the initial value. Figure 8 shows the measurement rates of internal damping of magnesium alloy AZ31 depending on the amplitude of deformation.

The second examined material was magnesium alloy with a higher aluminum content (6.880 wt. \%), the AZ61 alloy. The experiment conditions and input parameters remained the same as for the AZ31 alloy. The AZ61 was measured from $1 \mathrm{~V}$ to $7 \mathrm{~V}$ (Fig. 9), but the test bar was broken during measurement up to $7 \mathrm{~V}$. The cause of bar damage was the higher proportion of defects present in this specimen. Amplitude dependencies of the internal damping of the AZ61 alloy were similar in character to previous measurements. With increasing amplitude of the vibration voltage, the internal damping first decreased.

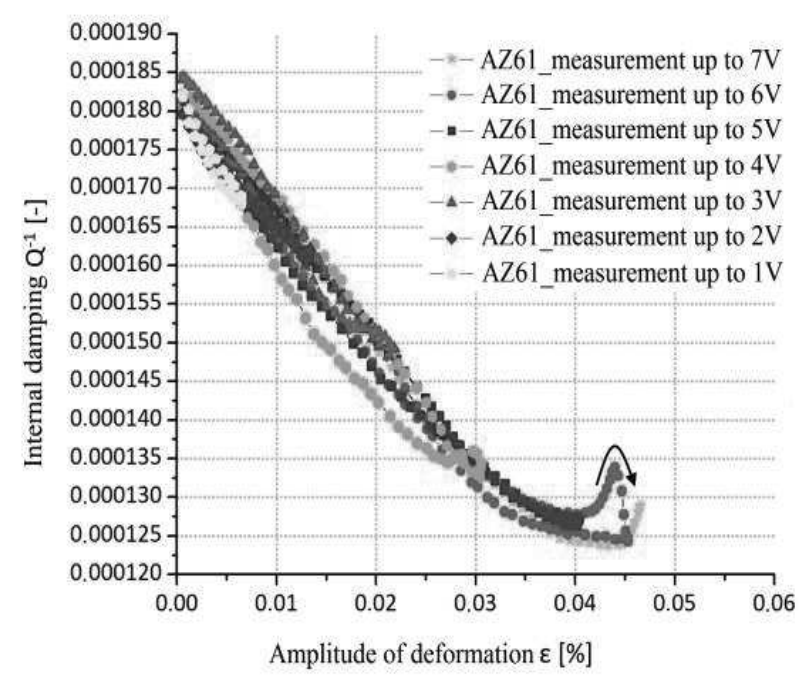

Fig. 9 Amplitude dependence of the internal damping of AZ61 magnesium alloy

Six measurements were made on the AZ31 magnesium alloy with a different degree of plastic deformation (Fig. 10). The course of the measurements was similar to that of the AZ31 magnesium alloy without a plastic deformation, i.e. with the increasing amplitude of the load, the internal damping first decreased, then followed the amplitude-independent zone and the critical amplitude of deformation was subsequently recorded from which the internal damping began to grow. The critical amplitude of deformation was shifted to the higher amplitude of deformation during the first four measurements. Amplitudes that were sufficient in one measurement to tear off dislocations from weakly anchored points, were no longer sufficient in the next measurement and higher amplitudes of deformation had to be applied to tear. The gradual increase of the amplitude of deformation is the result of increased density of dislocation segments, but the impact of this shift also results in plastic deformation, during which the density of dislocations increases and the material hardens.

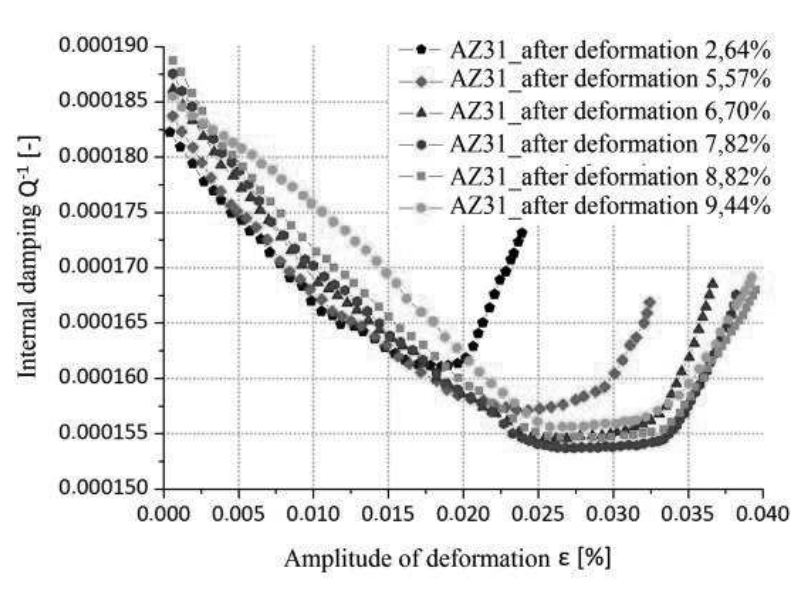

Fig. 10 Amplitude dependence of the internal damping of AZ31 magnesium alloy after plastic deformation

The plastic deformation on the surface of the AZ31alloy sample is documented in Figure 11. Because deformation was only in one direction, deformation occurred only in crystallographically appropriately directed grains. The deformation was limited by grain boundaries, at which the slip lines stopped. In magnesium alloys, twinning is the dominant way of deformation at low temperatures. During the load application, germs of twins are formed, followed by deformation twins, which are very often overlapping. The projection of the plastic deformation realized by the combination of segments of screw and edge dislocations is shown in Figure $11 \mathrm{~b}$.

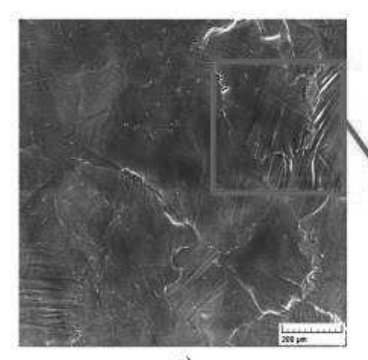

a)

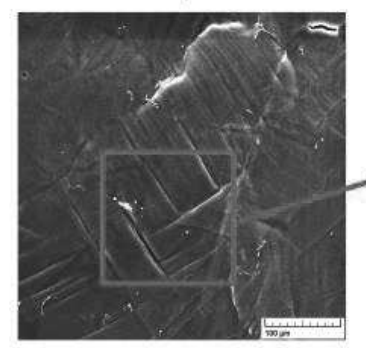

c)

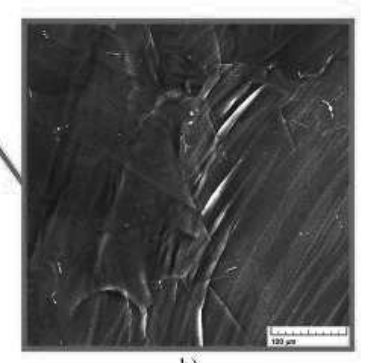

b)

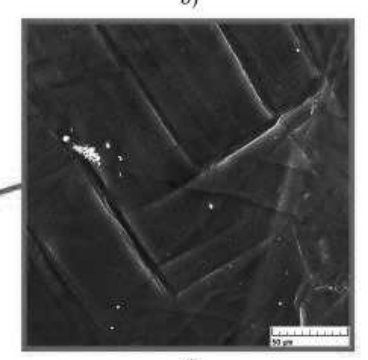

d)
Fig. 11 Microstructural analysis of AZ31 magnesium alloy after plastic deformation, a) combination of segments of screw and edge dislocations - 200x magnification, b) detail - 500x magnification, c) overlapping of deformation twins - 500x magnification, d) detail 1000x magnification

The measurement of the dependence of the internal damping on the amplitude of deformation on the AZ61 magnesium alloy was carried out on two test bars, on the sample 1 and the sample 2, respectively (Fig. 12). With 
the increasing amplitude of the load, the internal damping first decreased, then followed the amplitude-independent zone and the critical amplitude of deformation was subsequently recorded from which the internal damping began to grow. Two measurements were made on sample 1 , and after a third degree of plastic deformation, the test bar broke. The second measurement has shown a significant decrease in internal damping compared to the first measurement and moved to the right to higher amplitude of deformation. Because the sample 1 was damaged under relatively low deformation, lower percentages of deformation were selected for sample 2 . Three courses of internal damping were measured on sample 2. In sample 2, with the increase in plastic deformation, The critical amplitude of the deformation shifted to the right, probably because of the density of the dislocation segments but also because the density of the deformations and twins due to the plastic deformation increased in the microstructure. The saturation effect did not occur during the measurement due to the fact that the plastic deformation was too low.

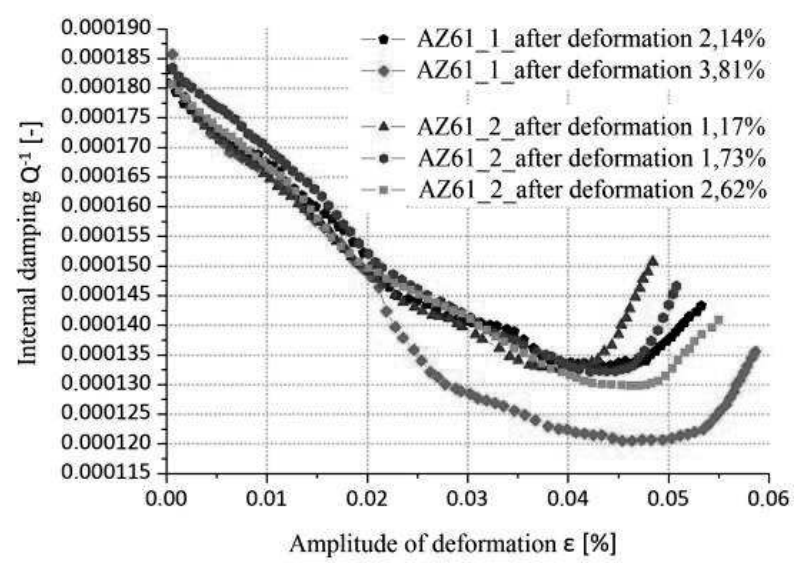

Fig. 12 Amplitude dependence of the internal damping of AZ61 magnesium alloy after plastic deformation

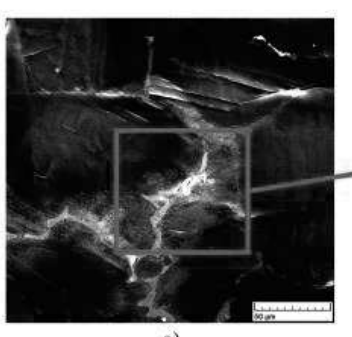

a)

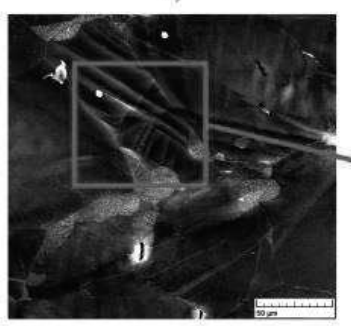

c)

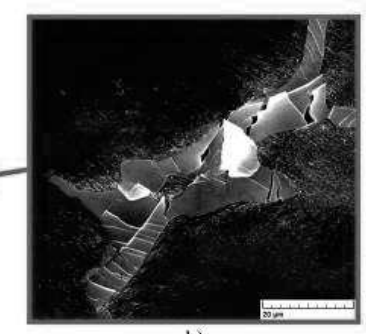

b)

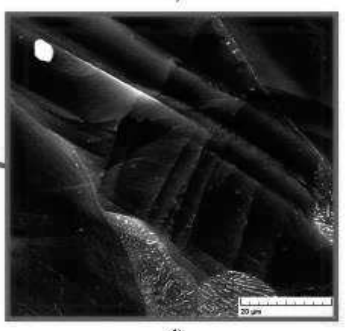

d)
Fig. 13 Microstructural analysis of AZ61 magnesium alloy after plastic deformation, a) brittle failure of the phase $\gamma-700 x$ magnification, b) detail - 3000x magnification, c) deformation twins - 1000x magnification, d) detail - 3000x magnification
The structural state of the AZ61 sample after plastic deformation is documented in Figure 13, but plastic deformation only occurred in grains which had a suitable crystallographic orientation. The AZ61 alloy displayed the greatest volume of discontinuous precipitate from all the materials tested. Its presence in the microstructure acted as a natural obstacle to defining the expression of plastic deformation. The Figure 13b illustrates the brittle failure of the phase $\gamma$, showing that the deformation of the discontinuous precipitate was minimal.

\section{Conclusions}

Examined alloys varied with the content of the major alloying elements, which could thus be expected to have a significant impact on the measured course of amplitude dependencies of internal damping. However, this hypothesis has not been confirmed, when we make a compare of measurements for example for $6 \mathrm{~V}$ or $7 \mathrm{~V}$. The internal damping values were comparable for both alloys. It has been assumed that with increasing content of alloying elements, the critical amplitude of the deformation will occur at higher amplitude of deformation. For example, in measurements of up to $6 \mathrm{~V}$, the critical amplitude of the deformation was achieved with almost the same amplitude of deformation for both alloys. For AZ31 alloy, the critical amplitude of the deformation shifted to the right, but this shift was minimal. This material behavior indicates that despite its different chemical composition, the number of free atoms in the solid solution is approximately the same.

Measurements of internal damping of alloys after plastic deformations were similar in character to measurements on test bars without plastic material conversion. That is, the internal damping first decreased with increasing of the amplitude of deformation, and then the critical amplitude of the deformation was recorded at certain amplitude of deformation, from which the internal damping increased. The critical amplitude of the deformation shifted to the right after each degree of plastic deformation. It is possible that even in this case, the density of dislocation segments has a certain impact on the critical amplitude of the deformation shift. However, it is likely that the greater effect on this shift is that the density of dislocations and deformation twins increases during plastic deformation, so the material hardens. Deformation amplitudes sufficient to achieve the critical amplitude of the deformation (to tear away dislocations from weakly anchored points) in one run are already inadequate. In order to tear, it is necessary to apply higher amplitudes of deformation. Comparing the amplitude dependences of the internal damping of the individual alloys after the plastic deformation, it can be seen that the critical amplitude of the deformation did not occur at the same amplitude of deformation and even at the same level of internal damping. Whereas on test bars that were not plastically deformed, the critical amplitude of the deformation occurred approximately at the same amplitude of deformation. This effect is probably related to the strength or the hardness of the material after plastic deformation. The stronger the material, the higher the amplitude of deformation needed to break dislocations from weakly anchored points. 


\section{Acknowledgement}

This work has been supported by Scientific Grant Agency of Ministry of Slovak Republic and Slovak Academy of Science, No. 013ŽU-4/2019. This work was supported under the project of Operational Programme Research and Innovation: Research and development activiries of the University of Zilina in the Industry of 21 st century in the field of materials and nanotechnologies, No. 313011T426. The project is co-funding by European Regional Development Fund.

\section{References}

[1] XU, Y., HU, L., SUN, Y., JIA, J., JIANG, J., MA, Q. (2015). Microstructure and mechanical properties of AZ61 magnesium alloy prepared by repetitive upsetting-extrusion. In: Transactions of Nonferrous Metals Society of China, Vol. 25, No. 2, pp. 381-388. ISSN 1003-6326.

[2] VOJTĚCH, D., KUBÁSEK, J., VODĚROVÁ, M., ŠERÁK, J. (2014). Structure and mechanical properties of Mg-based alloys for elevated temperature applications. In: Manufacturing Technology: journal for science, research and production. Vol. 14, No. 3, pp. 482-487. ISSN 1213-2489.

[3] KUBÁSEK, J., VOJTĚCH, D., DVORSKÝ, D. (2016). Effect of microstructure on the mechanical properties of binary magnesium alloys containing Ga, In and Sn. In: Manufacturing Technology: journal for science, research and production. Vol. 16, No. 5, pp. 971-978. ISSN 1213-2489.

[4] PUŠKÁR, A., GOLOVIN, S. (1981). Kumulácia poškodenia v procese únavy, pp. 263. VEDA Publisher, Bratislava.

[5] SOVIAROVÁ, A. (2015). Vplyv obsahu hliníka na zmenu vnútorného tlmania $v$ závislosti od teploty v horčikových zliatinách - dissertation thesis. University of Žilina.

[6] HURTALOVÁ, L., TILlOVÁ, E., CHALUPOVÁ, M., BELAN, J., VAŠKO, A. (2014). Microstructure control of secondary A 231 cast alloy used in automotive industry. In: Manufacturing Technology: journal for science, research and production. Vol. 14, No. 3, pp. 326333. ISSN 1213-2489.

[7] BELAN, J., KUCHARIKOVÁ, L., VAŠKO, A., TILLOVÁ, E. (2016). Applied heat treatment and its influence on IN 718 alloy fatigue life. In: $M a-$ nufacturing Technology: journal for science, research and production. Vol. 16, No. 5, pp. 865870. ISSN 1213-2489.

[8] DRESSLEROVÁ, Z., PALČEK, P. (2014). Temperature dependence of the internal friction measured at different excitation voltage. In: $M a$ nufacturing Technology: journal for science, research and production. Vol. 14, No. 3, pp. 287290. ISSN 1213-2489. 